\title{
Some Experiments on the Interaction between Propeller and Rudder.
}

\author{
By Hisamitsu Shiba, Kogakushi.
}

Contents.

I. Introduction.

II. A Resistance Measuring Apparatus.

III. Rudder Resistance in Open Water.

IV. Combined Test of Rudder and Propeller.

V. Self Propulsion Test of Model Ship.
a) Comparisons between Ordinary Stream Line Rudder and Partially Swelled Rudder.
b) Some Considerations upon Reaction Rudder.

VI. Conclusions.

\section{Introduction.}

Since the propulsive performance of a ship is effected by its rudder, especially so for a single-screw ship, it is quite necessary to examine the interaction between propeller and rudder.

It is, however, a matter of great regret, so far as I am aware, that the results of model researches on this subject have not yet been published except those by $\mathrm{Mr}$. Yamagata, who presented a paper entitled "Experiments on the Mutual Action between Propeller and Rudder" at the spring meeting of the Society of Naval Architects of Japan held in 1933.

This paper also deals with the interaction between propeller and rudder from propulsive point of view, especially the relation between the radial variation of the propeller pitch and the distribution of the sectional area of the rudder.

For this purpose I designed a special kind of rudder, i.e. a partially swelled rudder which is partially swelled behind the propeller boss and as thin as possible at the upper and lower parts, and also I designed a decreasing pitch propeller.

This partially swelled rudder was compared with an ordinary stream line rudder and also with a reaction rudder through combined experiments of propeller and rudder as well as through resistance experiments in open water. Moreover, the propulsive 
performance of the ship fitted with the partially swelled rudder was compared with that of the same ship fitted with an ordinary stream line rudder through self propulsion tests, the ship being propelled by turns by decreasing and increasing pitch propellers.

Also the propulsive performance of a ship fitted with a reaction rudder propelled by an increasing pitch propeller was compared with that of the same ship propelled by a decreasing pitch propeller.

Again a similar test was made with another ship with different increasing and decreasing propellers.

For notations used here, see Mr. M. Yamagata's paper.

\section{Rudder Resistance Measuring Apparatus.}

Owing to the small size of rudders which were fitted to model ships of the length of 6 meters, their resistances were too small to be measured by a resistance dynamometer which is usually used in measuring the resistance of a model ship.

The measuring apparatus used at the present experiments was one which was specially designed at the Teishinsho Ship Experiment Tank to measure accurately such small resistances; which details are given in Mr. Yamagata's paper mentioned above.

\section{Rudder Resistance in Open Water.}

The resistances of two rudders, i.e. an ordinary stream line rudder and a partially swelled rudder were measured in open water. These rudders had the same area projected on the center plane.

The reaction rudder, used in the combined experiments, was selected because it bears, among our rudders at hand, the closest resemblance to the rudders described above in its area projected on the center plane. The resistance test of this rudder in open water was omitted since similar tests are given in the above mentioned paper.

These three rudders are shown in Fig. 1. The resistances of the two rudders was plotted upon the speed base on logarithmic paper as shown in Fig. 2. The resistance of the partially swelled rudder was, as the figure shows, smaller than that of the ordinary stream line rudder by about $30 \%$. I think this was because the former rudder was probably thinner than the lattar in its average thickness.

IV. Combined Test of Propeller and Rudder.

In studying the interaction between propeller and rudder, two propellers and 
three rudders were employed. These two propellers, No. 85 and No. 85A, were different from each other only in radial distribution of pitch, and they are illustrated in Fig. 3.

The thrust and torque of each propeller together with the resistance of each rudder were measured at the same time at any advance speed, each propeller revolving about 9.9 turns per second.

In these combined experiments the propeller dynamometer was made to move backwards, since the rudders had to be arranged behind the propellers as shown in Fig. 4. Therefore, corrections are necessary to the test results owing to the interventions of the brackets, etc. The explanations of how to correct in such a case is omitted here, since it is described in detail in Mr. Yamagata's paper. In these particular experiments, however, such corrections were entirely omitted, as my chief object was to get the best combination between the propeller and rudder.

The combined experiments of the reaction rudder and the propeller No. 85 were omitted, as similar experiments had already been made by Mr. Yamagata and are shown in his paper.

Now from these results, the thrust constant and torque constant as well as the propeller efficiency and nominal slip are calculated and plotted upon the base of advance constant in Figs. 5 and 7.

As the propeller efficiency may be considered to depend upon the thickness of the rudder, the propeller efficiency at the combined experiments of the propeller and the partially swelled rudder must be lower than that of the propeller and the ordinary stream line rudder, since the partially swelled rudder may be considered thinner than the ordinary stream line rudder, judging from the resistance experiments of the two rudders in open water already described in Paragraph III.

On the other hand, so far as propeller efficiency is concerned, there is little to choose between the two rudders, as will be seen in Fig. 5. This will be due to the fact that the decrease in the propeller efficiency caused by the thinner part of the partially swelled rudder is made up for by the increase caused by its swelled part.

Thus we may say that the swelled part contributes to the propeller efficiency.

In order to prove this it will be sufficient to examine the propeller No. 85 combined with the partially swelled rudder, in whioh case the augmentation of slip stream will be higher near the swelled part of the rudder. Here, as is clearly seen from the experiments on the propeller No. 85.A shown in Fig. 7, its propeller efficiency when combined with the partially swelled rudder $321 \mathrm{~A}$ is higher than when combined 
with the ordinary stream line rudder No 321 .

As for the rudders, their resistance constants in the dimensionless form, calculated from the results of the combined experiments, are plotted upon the base of the advance speed constant as shown in Figs. 6 and 8 . The resistance constants calculated from the resistance at the speed of NP, i.e. the pitch multiplied by the revolutions, in meter per second in open water tests, are also illustrated here, together with the nominal slip.

In these experiments, as the maximum difference of temperature of the tank water was only $3^{\circ} \mathrm{C}$, Reynolds' number may be assumed to be constant.

For the propeller No.85, the resistances of the partially swelled rudder and the ordinary stream line rudder at the combined experiments were greater than the corresponding resistances in open water. But this increment for the partially swelled rudder is smaller than that for the ordinary stream line rudder.

On the other hand, for the propeller No.85A, the resistance of the former at the combined experiments is smaller than its corresponding resistance in open water, and that of the latter remains unaltered, as will be seen in Fig. 8.

From these experiments, it may be said that the swelled part contributes to the thrust.

The thrust of the reaction rudder No. 206 by the propeller No. $85 \mathrm{~A}$ begins to be produced at about $22 \%$ slip and it begins to increase suddenly at about $40 \%$, as shown in Fig. 8.

\section{Self Propulsion Test of Model Ship.}

a) Comparison between Ordinary Stream Line Rudder and Partially Swelled Rudder.

The model ship No. 321, 6 meters in length, was tested self-propelled with both the propellers Nos. 85 and $85 \mathrm{~A}$, the model ship being fitted with the ordinary stream line rudder No. 321 and the partially swelled rudder No. 321A by turns.

The propeller No. 85 was specially designed for this model ship by the Teishinsho method and is what is called a wake propeller.

The principal dimensions and coefficients, etc. of the actual ship are as follow:

Length between perpendiculars. .............................

Breadth moulded. ............................ 19.000 "

Depth moulded. ....................................... $10.500 "$

Draught moulded. ........................... $8167 "$ 


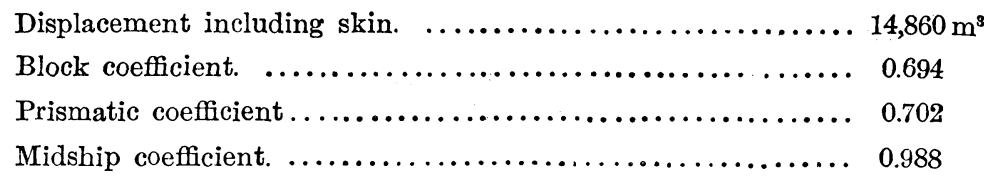

These experimental results are shown in Figs. 9 and 10 in the dimensionless form, from which shaft horse power S.H.P. and propeller revolutions R.P.M. are calculated and plotted upon the base of speed in knots in Figs. 11 and 12.

It will be clearly seen from Fig. 12 that the best result can be obtained when fitted with the partially swelled rudder No.321A from the propulsive point of view, and when we consider the above mentioned combined experiments it was quite natural that such results should have been obtained.

As for the reaction rudder No.206, it is much to be regretted that I can-not give here the comparative merits between it and the partially swelled rudder from the propulsive point of view, because I have not yet made any self-propulsion test with it.

Therefore I was obliged to compare the propulsive performance of a ship fitted with the reaction rudder No. 206 propelled by the propeller No. $85 \mathrm{~A}$ with that of the same ship fitted with the partially swelled rudder No.321A by a calculation based upon some assumptions.

The calculations are as follow :-

$$
\begin{aligned}
& \eta \ldots \ldots \ldots \ldots \text {. Propulsive coefficient }=\frac{(\text { E.H.P. })_{a p p}}{\text { (S.H.P.) }} \\
& \eta_{p} \ldots \ldots \ldots \ldots \text {. Propeller efficiency open. } \\
& \eta_{r} \ldots \ldots \ldots \text {...... Relative rotative efficiency. } \\
& \eta_{h} \ldots \ldots \ldots \ldots \text {. Hull efficiency. } \\
& \text { w............. Wake fraction. } \\
& t \text {............ Thrust deduction coefficient. } \\
& \text { T........... Thrust of propeller. } \\
& \eta_{3214}=\eta_{h 3.14} \cdot \eta_{r 321 A} \cdot \eta_{p 3214} \\
& \eta_{206}=\eta_{h 2266} \cdot \eta_{r 206} \cdot \eta_{p 206}
\end{aligned}
$$

Then

$$
\frac{\eta_{321 A}}{\eta_{206}}=\frac{\eta_{h 321 A}}{\eta_{h 206}} \cdot \frac{\eta_{r 321 A}}{\eta_{r 206}} \cdot \frac{\eta_{p 3214}}{\eta_{p 2 C 6}}
$$

At the same speed, if we assume

$$
\begin{aligned}
& \eta_{r 321 A} \fallingdotseq \eta_{r 206} \\
& w_{321 A} \fallingdotseq w_{206}
\end{aligned}
$$


Then the above equation will become

$$
\begin{gathered}
\frac{\eta_{3214}}{\eta_{206}} \fallingdotseq \frac{1-t_{321 A}}{1-t_{206}} \cdot \frac{\eta_{p 321 A}}{\eta_{p 206}} \\
\text { or } \quad \frac{(\text { S.H.P. })_{206}}{\text { (S.H.P. })_{321 A}} \fallingdotseq \frac{T_{206}}{T_{321 A}} \cdot \frac{\eta_{p 321 A}}{\eta_{p 206}}
\end{gathered}
$$

Now the thrust of the model ship $T_{3214}$, corresponding to that of the actual ship when delivering 7,240 S.H.P. at 105 R.P.M. is $4.97 \mathrm{~kg}$. and the corresponding resistance difference between the two rudders at the combined experiments is calculated to be $0.184 \mathrm{~kg}$. from Fig. 8.

If the thrust $T_{206}$ be approximately equal to the thrust $T_{321 A}$ reduced by the amount of $0.184 \mathrm{~kg}$., then the equation will become

$$
\frac{(\text { S.H.P. })_{2 n 6}}{\text { (S.H.P. })_{321.4}}=\frac{4.97-0.184}{4.97} \cdot \frac{\eta_{p 2214}}{\eta_{p 206}}=0.963 \cdot \frac{\eta_{p 321 A}}{\eta_{p 206}}
$$

But, as will be seen from Fig. 7 , the propeller efficiency $\eta_{p 3214}$ is higher than $\eta_{p 2 c 6}$. Therefore, this ratio must be larger than 1 .

Take for example Fig. 7. This ratio is 1.043 at the slip of about 0.38 .

Then

$$
\frac{(\text { S.H.P. })_{206}}{\text { (S.H.P. })_{3: 11}} \fallingdotseq 0.963 \times 1.043=1.004
$$

Therefore, in this case, there will be nothing to choose between the two rudders in spite of the remarkable thrust of the reaction rudder.

I believe that through systematic experiments we can attain to a swelled rudder much superior to the one used here.

\section{b) Some Considerations upon Reaction Rudder.}

It may be perceived that the slip stream is most effective near the propeller boss for the decrease of resistance and the increase of thrust of a reaction rudder, when we compare the results of the combined experiments of a reaction rudder and an increasing pitch propeller with those of a reaction rudder and a decreasing pitch propeller.

As for the former experiments, see Mr. Yamagata's paper; for the latter, see Fig. 8 in this paper.

Now, since it has been noticed that the decreasing pitch propeller is effective for the generation of thrust of a reaction rudder, it would seem possible that, for a ship fitted with a reaction rudder, we get the best propulsive performance by adopting a 
suitable decreasing pitch propeller, despite some propeller efficiency loss.

Model ship No. 237 fitted with a contra rudder, 6 meters in length, was tested self-propelled in turn with the propellers Nos. 85 and $85 \mathrm{~A}$.

The principal dimensions and coefficients, etc. of the actual ship are as follow:

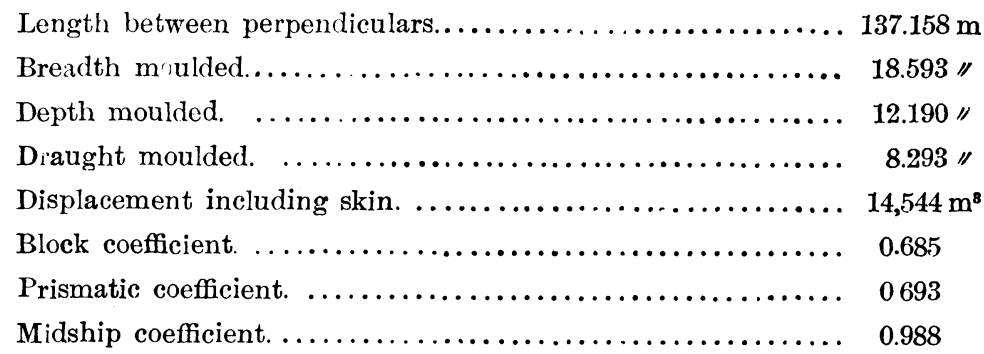

These experimental results are shown in Fig. 13 in the dimensionless form, from which shaft horse power S.H.P. and propeller revolutions R.P.M. of the actual ship are calculated and plotted upon the base of the speed in knots in Fig. 14.

As expected, the propulsive performance of the ship propelled by the decreasing pitch propeller is better than that of the same ship propelled by the increasing pitch propeller notwithstanding its worse propeller efficiency.

Next, the model ship No.247 fitted with a reaction rudder, 6 meters in length, was tested self-propelled by each of three propellers at the deep and light conditions.

The first of three propollers is one with increasing pitch, i.e. a so-called wake propeller designed by the Teishinsho method, the next with constant pitch and the third with decreasing pitch as shown in Fig. 15.

The principal dimensions and coefficients, etc. are as follow:-

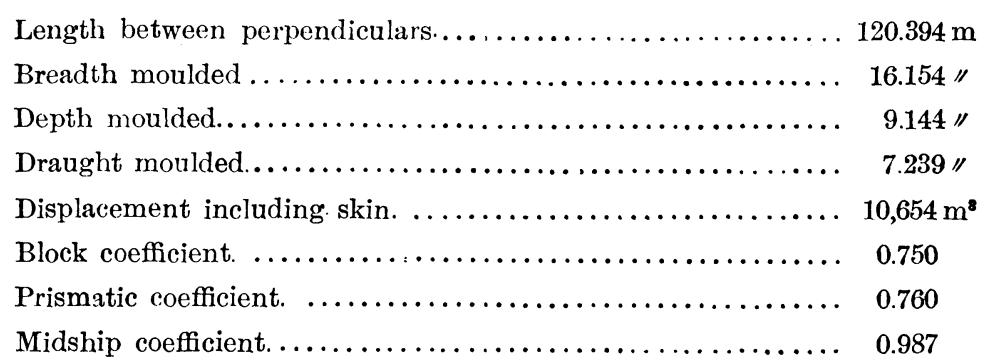

These experimental results are shown in Figs. 16 and 17 in the dimensionless form, from which shaft horse power S.H.P. and propeller revolutions R.P.M. of the actual ship are calculated and plotted upon the base of the speed in knots in Fig. 18 .

As it will ba clearly seen, the propulsive performance of the ship propelled by 
the decreasing pitch propeller is the best and that of the same ship propelled by the increasing pitch propeller is the worst at the full load condition.

In spite of the fact that the reverse is the case at the low speed at the light condition, we may regard these results to support the above supposition.

\section{Conclusions.}

In short, for good propulsive performance it is necessary to decrease rudder resistance and at the same time to increase propeller efficiency, and for this purpose we may attain a very desirable result by making the rudder swell at the part near the propeller boss, gaining by this device an increase of thrust and a higher propeller efficiency, and also by making the rudder as thin as possible towards its upper and lower parts, thus effecting a decrease of its resistance.

Further, in deciding the radial variation of propeller pitch we must consider the kind, the thickness and the distribution of sectional area of the rudder. For instance, for a ship fitted with a reaction rudder a decreasing pitch propeller is more effective than an increasing pitch propeller.

\section{討論}

○會長（藤島範平君） 只今の御講演に對し御質問、叉は御意見のある方は御願ひ致します。… 何方かありませんか。…ありません樣ですから一言御禮申上げます。志波君は舵亡 propeller に就 レ゙て、色々の場合を通じて色々の實驗を行はれ、本日御講演下さいました。誠に有监なる論文で將來 の造船設計上參考になる事頗る多いと思ひます。拍手を以て渚君と其に御䄈申上げます。(一同拍手) 
Some Exp riments on the Interaction between $\mathbf{P}^{\prime \prime}$ peller and Rudder.

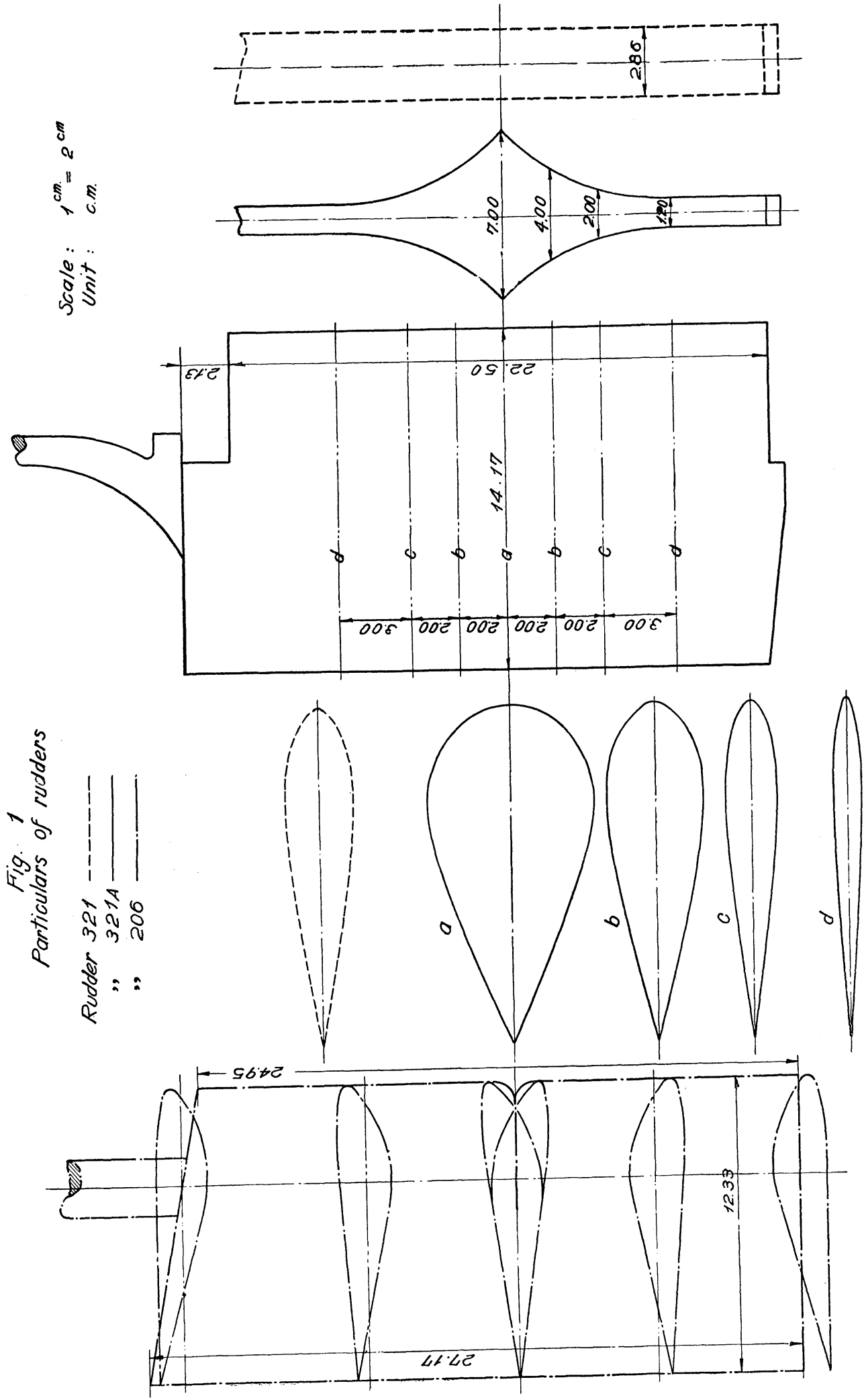



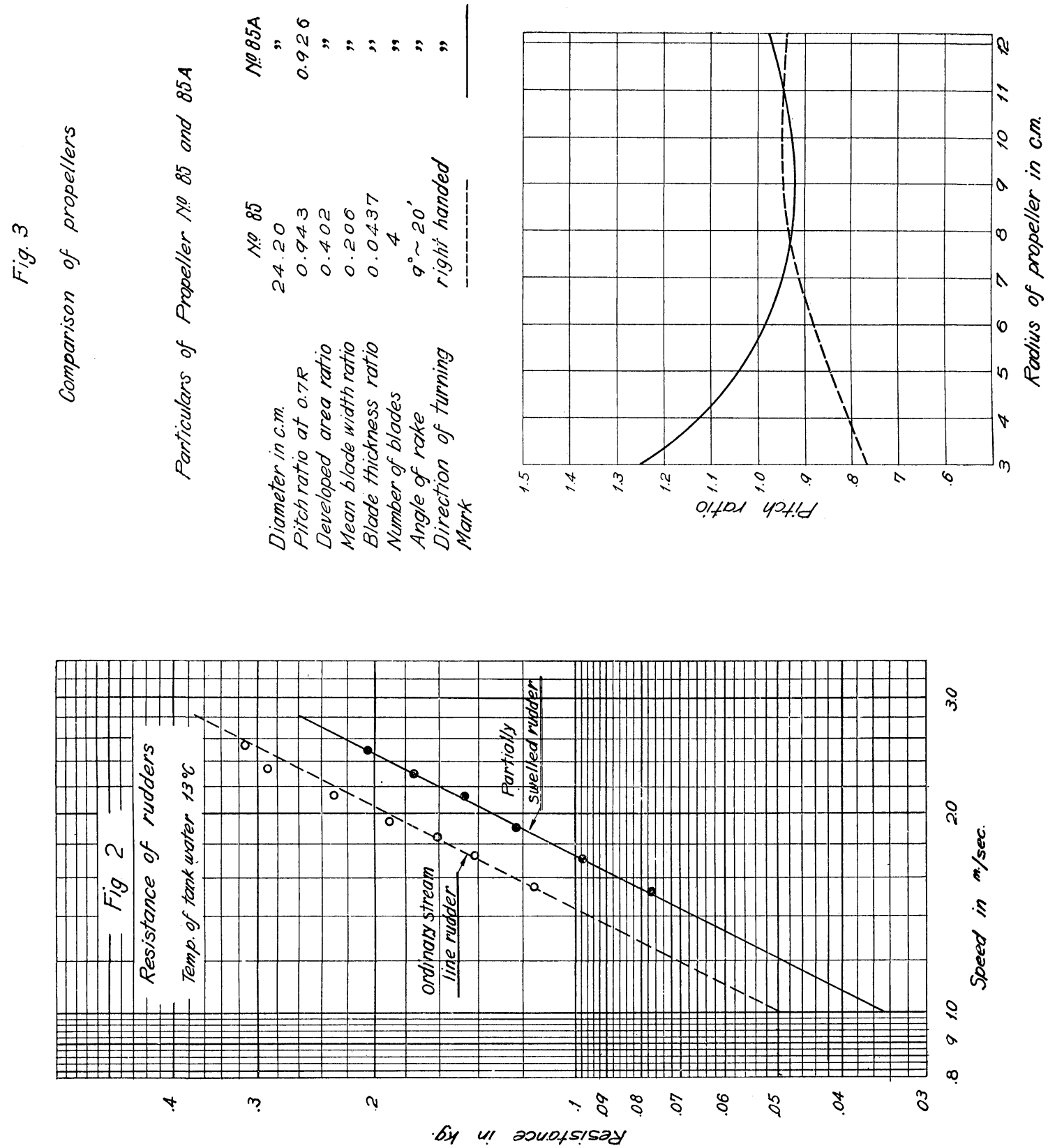

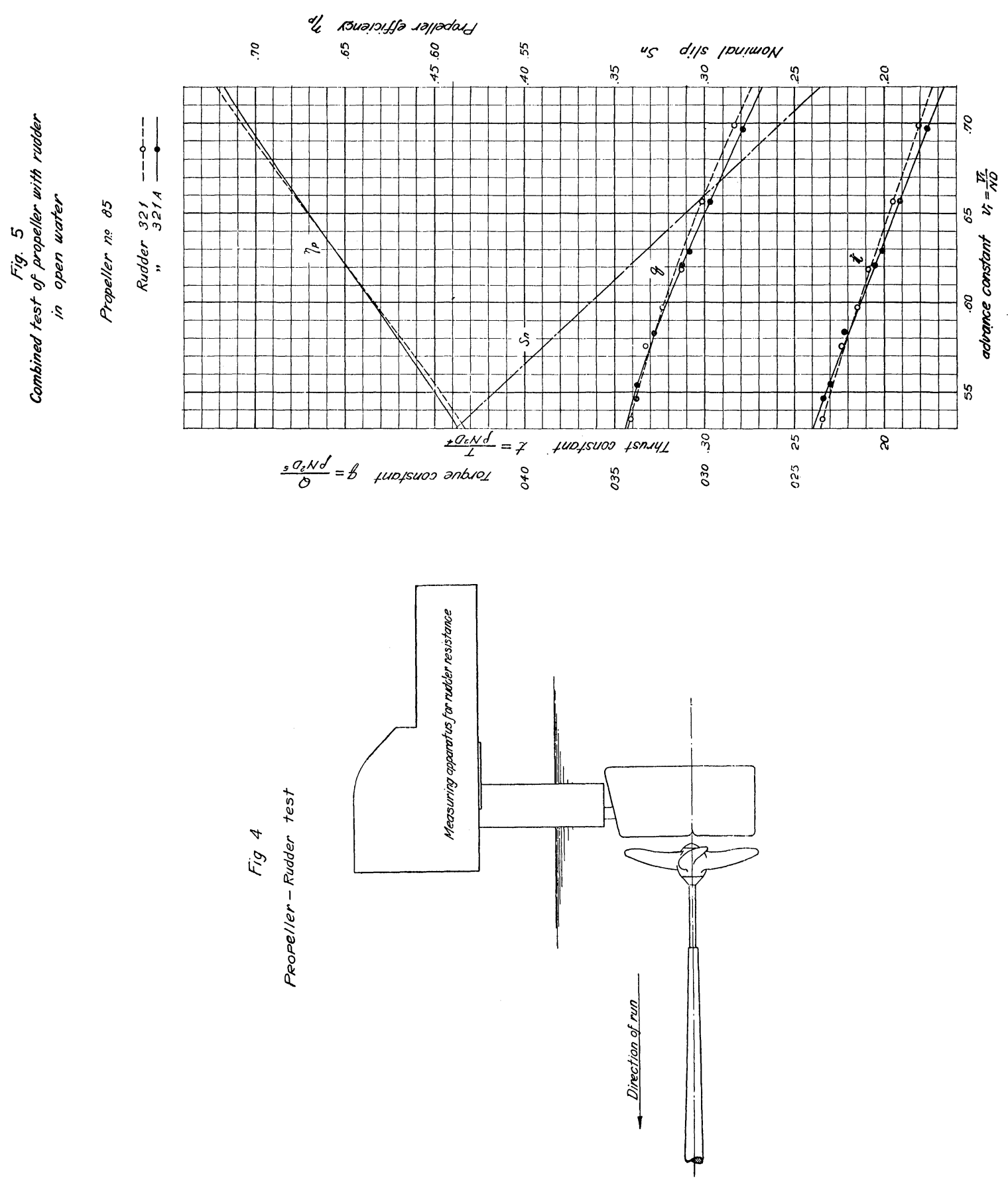

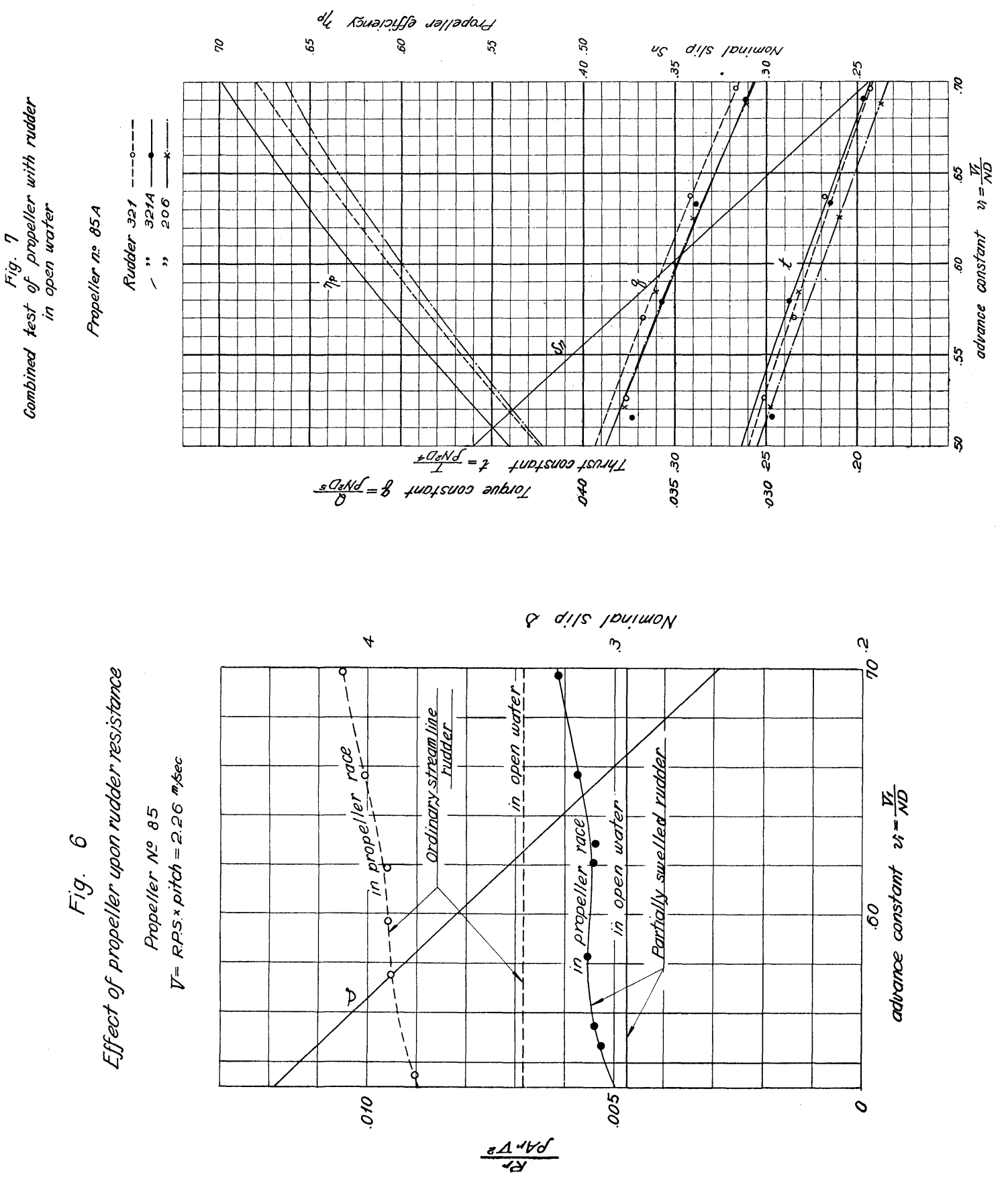

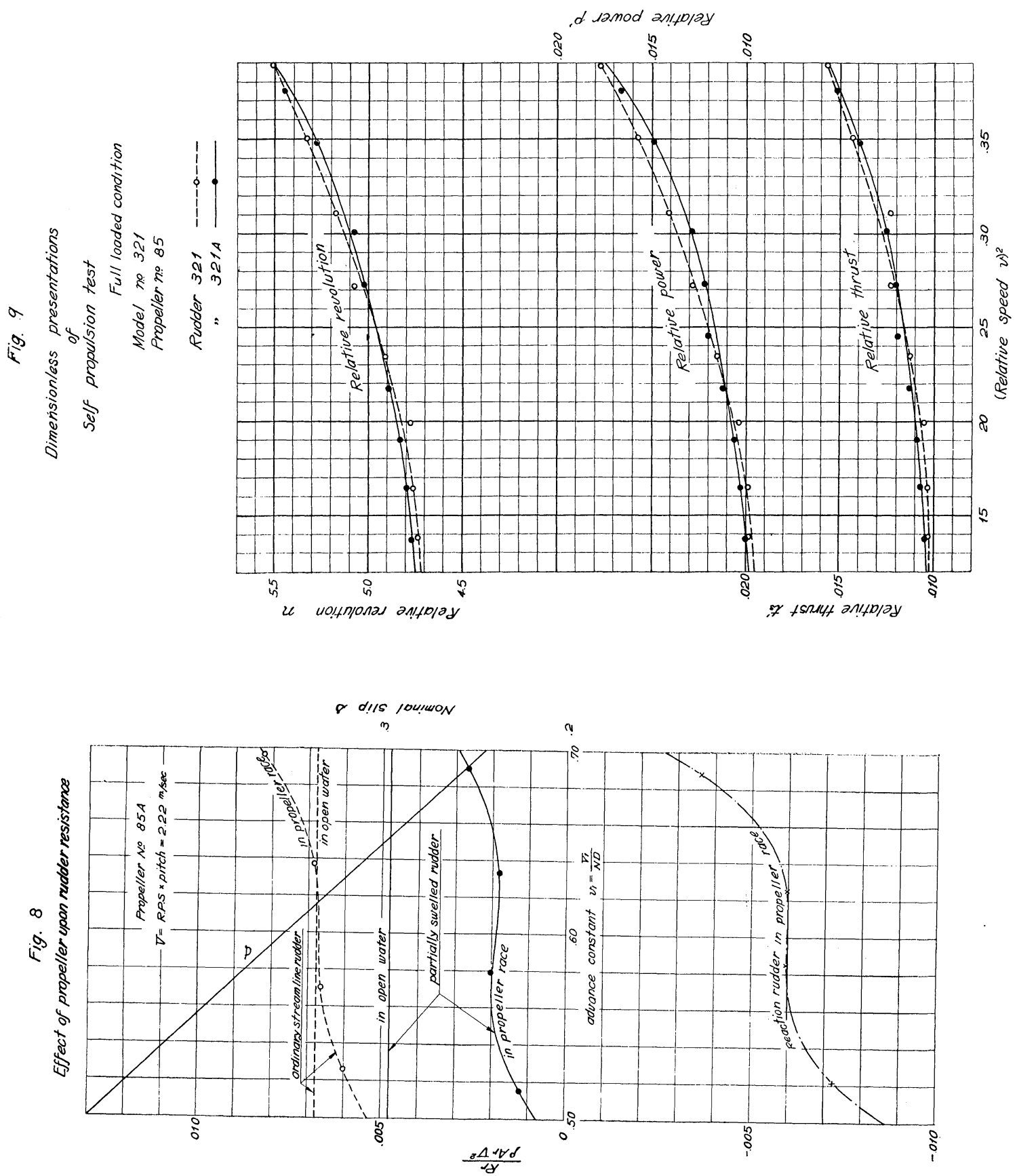
144

Hisamitsu Shiba:

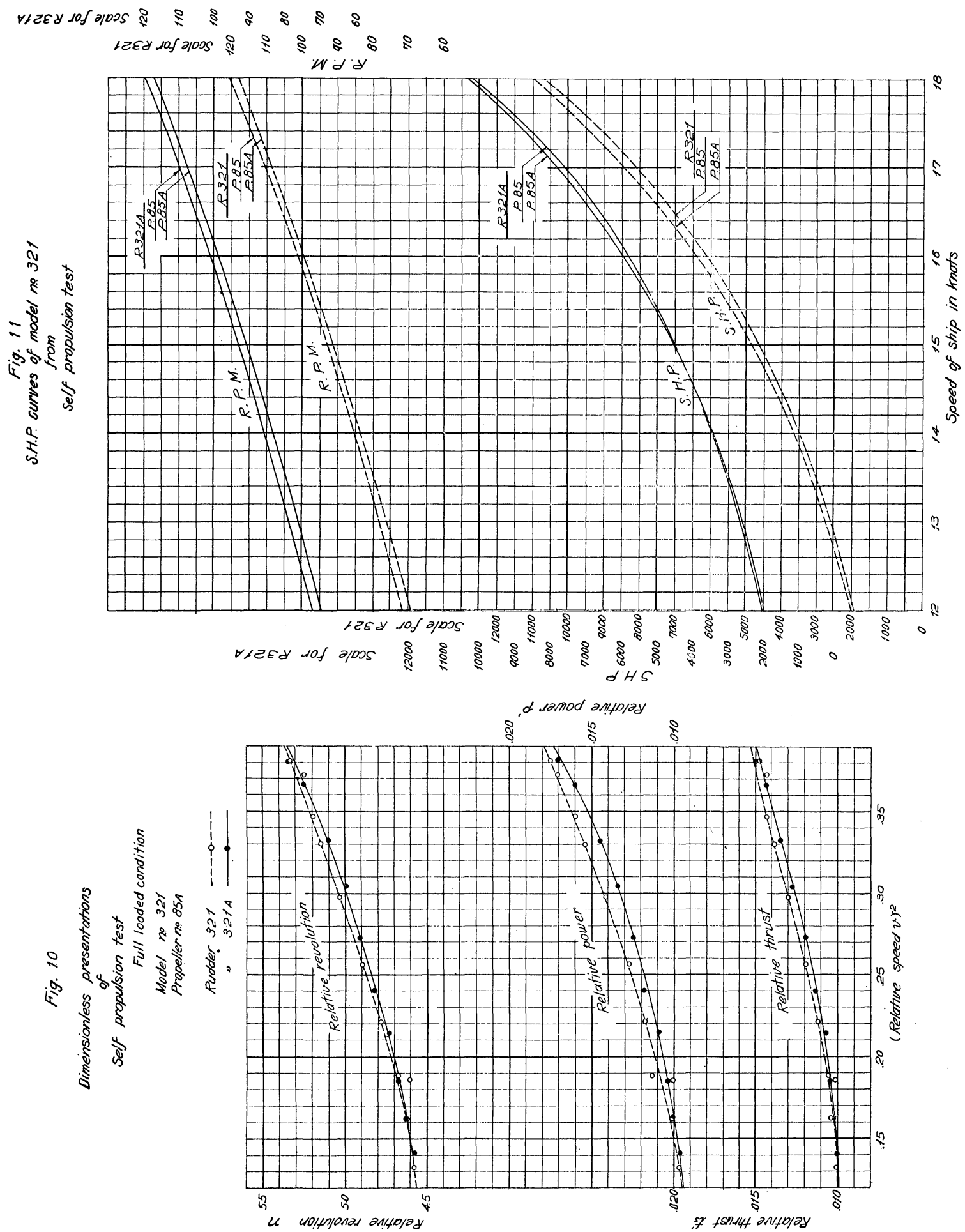



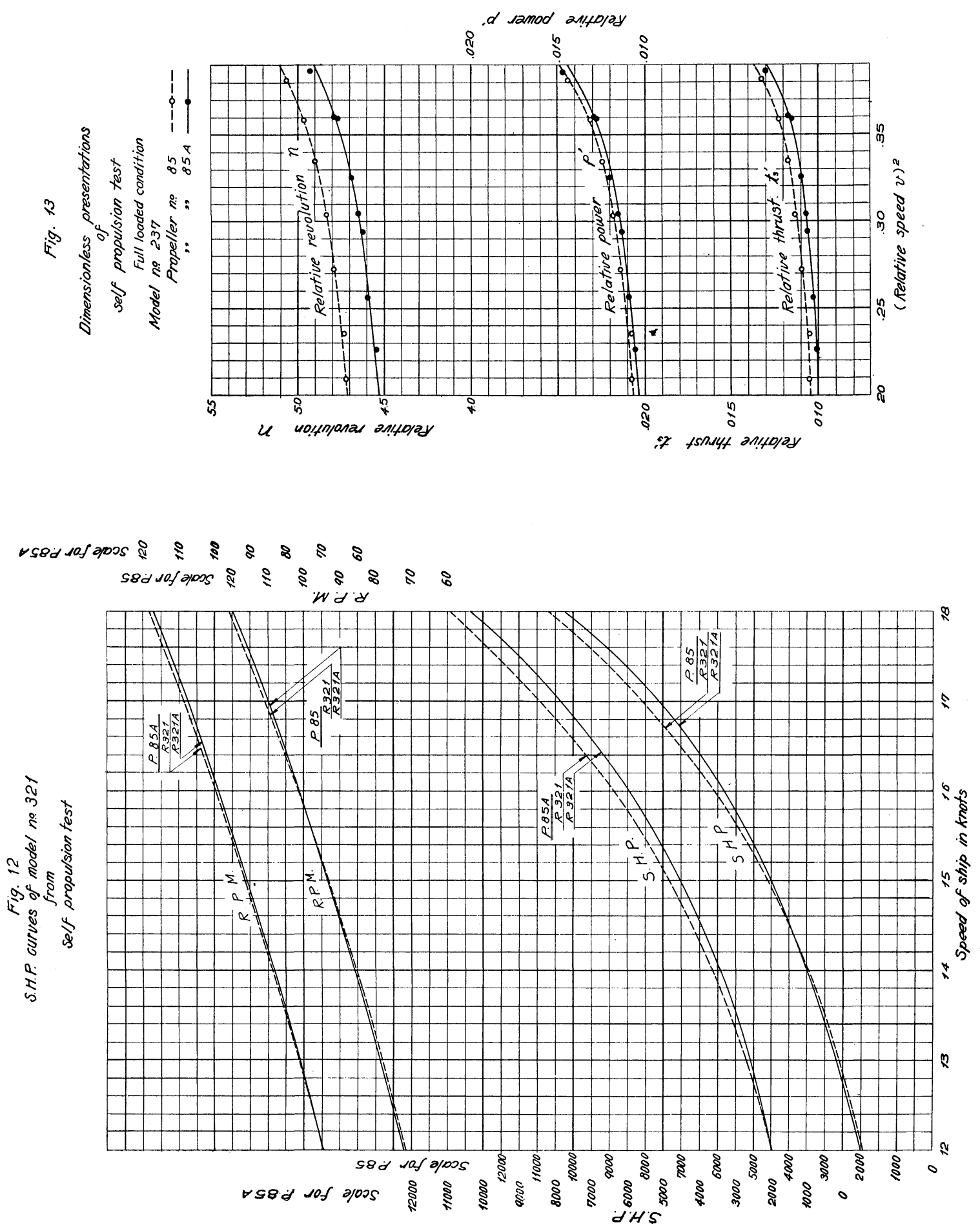

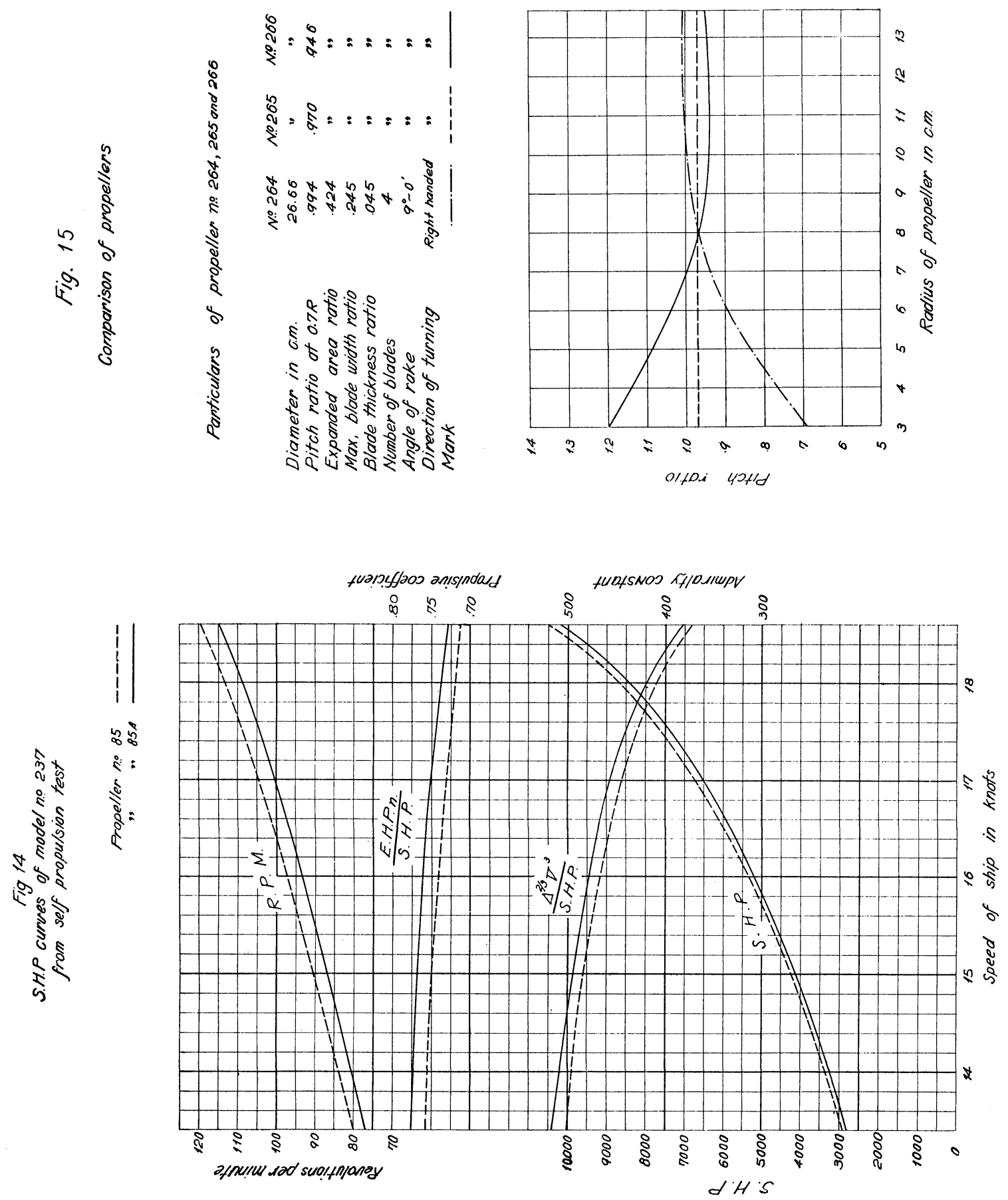

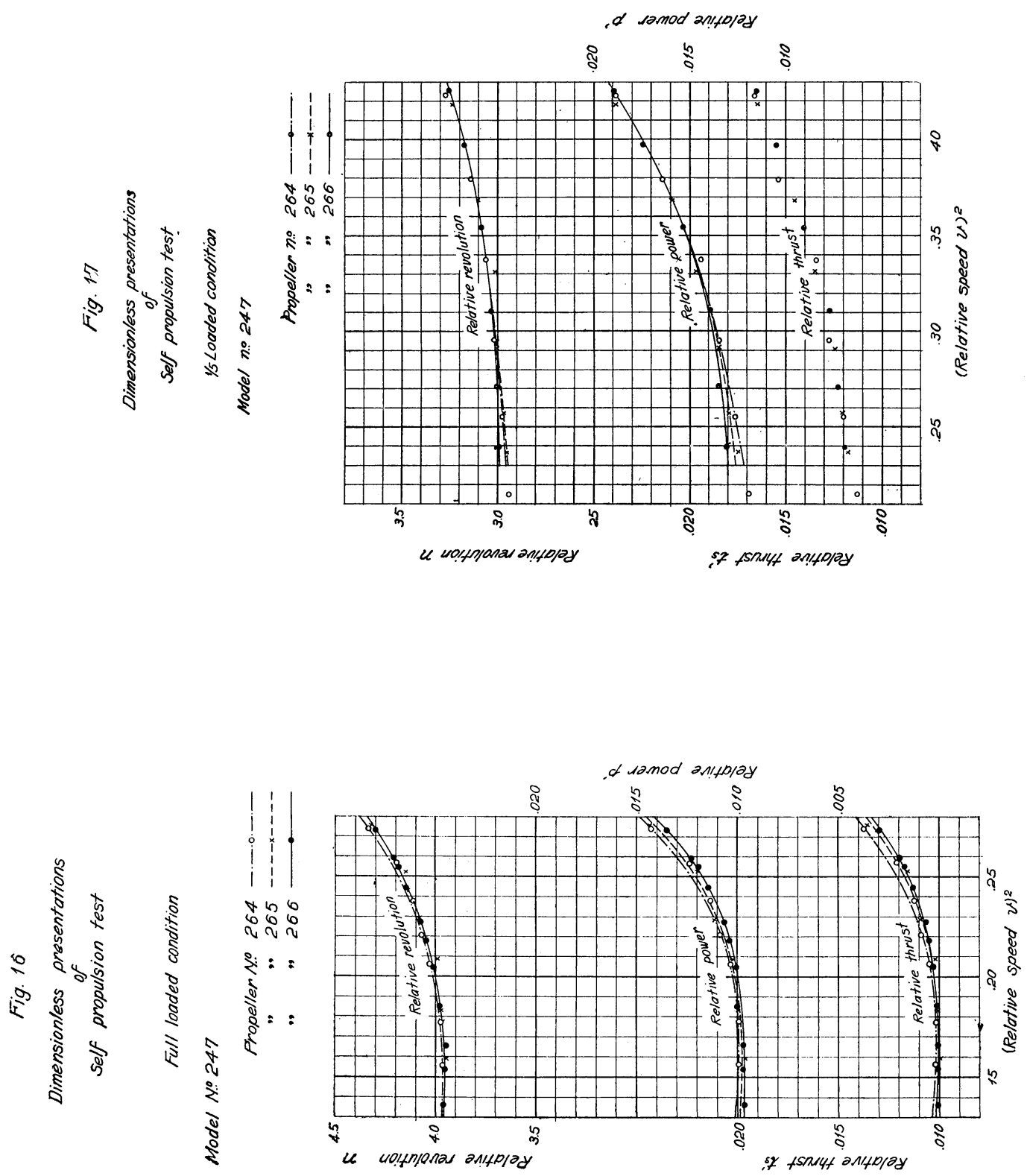


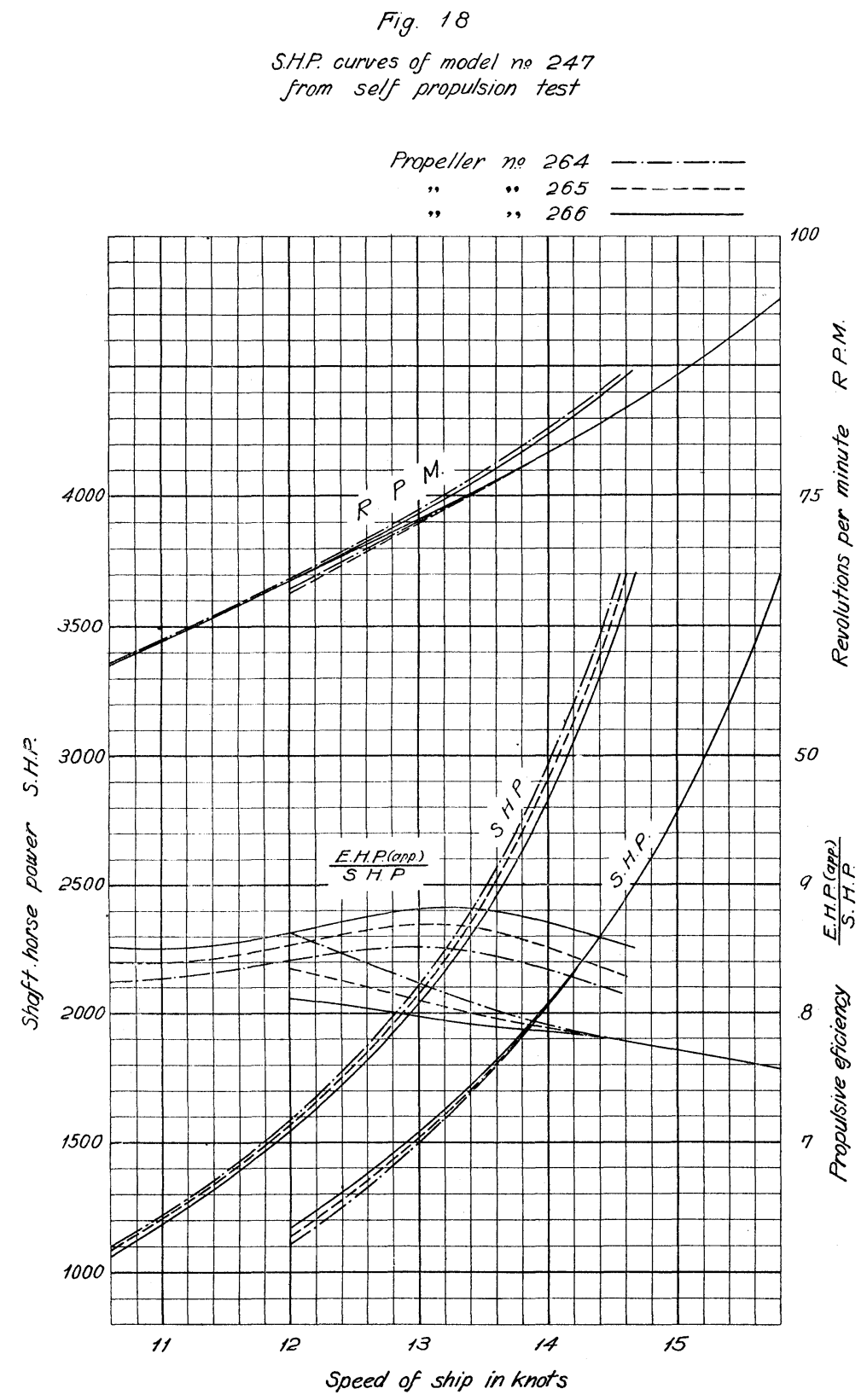

